\title{
EBSD Microstructural Analysis of WC-AISI 304 Cemented Carbides with Carbon Addition
}

\author{
C.M. Fernandes ${ }^{1}$, B.A. Almeida ${ }^{1}$, E. Soares ${ }^{2}$, J. Sacramento ${ }^{2,3}$ and A.M.R. Senos ${ }^{1}$ \\ ${ }^{1 .}$ Department of Materials and Ceramics Engineering, CICECO, University of Aveiro, 3810-193 Aveiro, \\ Portugal. \\ ${ }^{2}$ DURIT - Metalurgia Portuguesa do Tungsténio Lda, Albergaria-a-Velha, 3854-909, Portugal. \\ ${ }^{3}$ ESTGA - Higher School of Technology and Management, University of Aveiro, 3754-909, Águeda, \\ Portugal.
}

WC-AISI 304 stainless steel (SS) composites have been developed aiming at replacing the WC based cemented carbides using cobalt or nickel binder. Interesting mechanical properties compatible with their applications as hard and wear resistant materials can be attained in such a composites and it was shown in previous work that the carbon content has an important role on the final microstructure features and, so, on the final properties [1]. For the stoichiometric carbon, correspondent to the $\mathrm{WC}$, the $(\mathrm{M}, \mathrm{W})_{6} \mathrm{C}$ phase will be formed during heating up to the sintering temperatures, turning the composite fragile [2]. The content of $(\mathrm{M}, \mathrm{W})_{6} \mathrm{C}$ phase can be reduced or even eliminated through carbon addition to the powder. However, the "carbon window" to achieve microstructures free of undesirable phases, as $(\mathrm{M}, \mathrm{W})_{6} \mathrm{C}$ and graphite, in the WC-SS (Fe-Cr-Ni) system is narrow, turning the carbon control very critical to get composites with optimized properties $[3,4]$. Therefore, the objective of this work is to investigate the effect of the excess carbon on the microstructure, namely on the phase composition and grain size distribution.

WC composites with $10 \mathrm{wt} . \%$ of SS binder and carbon additions up to $1.2 \mathrm{wt} . \%$ were prepared from WC and AISI 304 SS powders, with an average particle size of $9 \mu \mathrm{m}$ and $5 \mu \mathrm{m}$, respectively, and carbon lamp powder. The carbon powder was added to adjust the composition into the "carbon window" of the two-phase region, based on related phase diagrams $[3,4]$. Four compositions were prepared and the respective composites are designated as WC-10SS for the sample without any carbon addition and WC10SS-xC, for the samples with carbon additions, being $\mathrm{x}$ the weight percentage of carbon $(\mathrm{x}=0.5,1.0$ and 1.2), The composites were processed through powder metallurgical routes (milling, pressing and vacuum sintering) and a more detailed description of the processing can be found elsewhere [1].

The polished microstructures (until $1 \mu \mathrm{m}$ diamond paste) of the WC composites were first observed by Scanning Electron Microscopy with Energy Dispersive Spectroscopy (SEM/EDS, Hitachi SU-70, detector Bruker, Quantax 400). The SEM images show that the added carbon clearly reduced the amount of $\eta$-phase and for $1 \mathrm{wt} \%$ of added carbon the mixed carbide phase is only residual, while it is completely eliminated for $1.2 \mathrm{wt} \%$. Other microstructural features seem to be affected by the excess carbon, such as the grain size distribution, needing a more detailed and quantified analysis of the developed microstructures by Electron Backscatter Diffraction (EBSD, Bruker e-Flash) and using the ESPRIT CrystAlign software. To prepare well polished surfaces, as required for EBSD analysis, the samples were mechanically polished with diamond paste until $1 / 4 \mu \mathrm{m}$, followed by $0.03 \mu \mathrm{m}$ colloidal silica suspension. The grain size distribution maps and the respective histograms were acquired and are presented in Fig.1. The grain size range is similar in all compositions $(0-2 \mu \mathrm{m})$, however with the increase of the carbon content it is observed a progressive reduction of the smallest grains population 
and increasing of the percentage of the larger grains, characteristic of a more intensive normal grain growth during the sintering step. Consequently, the average grain size, $G_{a v g}$, increases from $\mathrm{G}_{\mathrm{avg}}=0.664 \mu \mathrm{m}$ for the composite without carbon, WC-10SS, up to $\mathrm{G}_{\mathrm{avg}}=1.06 \mu \mathrm{m}$ for the composite WC10SS-1.2C (Fig.1). The increase of the grain boundary mobility with carbon addition can be caused by the decreasing pinning effect of secondary phases (reduction of the eta-phase content), or by alteration of the liquid phase amount and/or composition at the sintering temperatures, increasing the mass transport by solution-precipitation at the grain boundaries [5].

\section{References:}

[1] C.M. Fernandes et al., Materials Science \& Engineering A 618 (2014) p. 629-636.

[2] C.M. Fernandes et al., Int. Journal of Refractory Metals \& Hard Materials 25 (2007) p. 310-317.

[3] C.M. Fernandes et al., Int. Journal of Refractory Metals \& Hard Materials 29 (2011) p. 405-418.

[4] R. González et al., Journal Materials Science 30 (1995) p. 3435-3439.

[5] The author C.M. Fernandes gratefully acknowledge the financial support from the program COMPETE and by national funds through FCT under the grant SFRH/BPD/43402/2008. This work was developed within the scope of the project CICECO-Aveiro Institute of Materials (Ref. FCT UID /CTM /50011/2013), financed by national funds through the FCT/MEC and when appropriate co-financed by FEDER under the PT2020 Partnership Agreement.
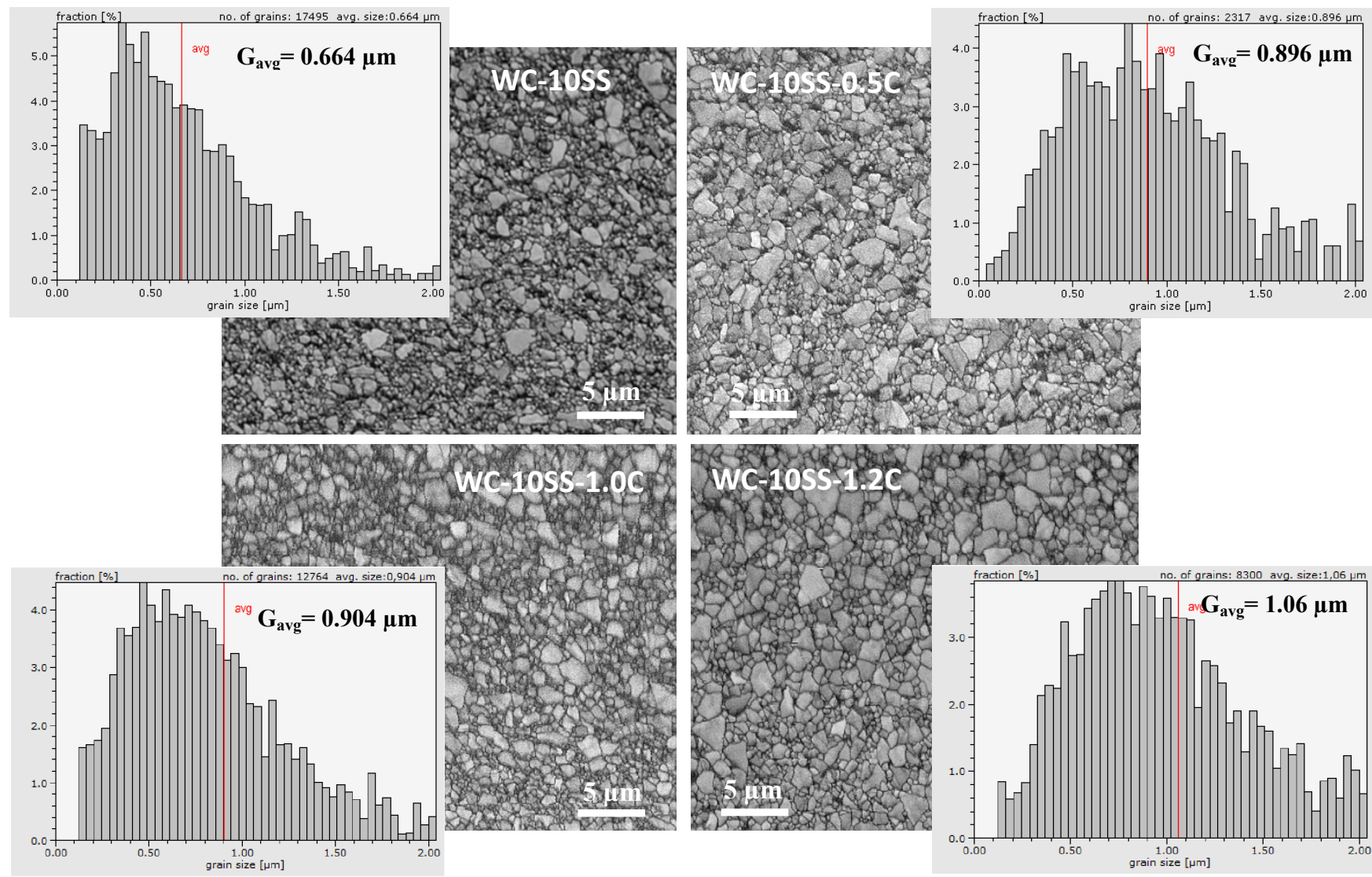

Figure 1. EBSD grain size maps and respective grain size distribution histograms for WC-10SS, WC-10SS-0.5C, WC-10SS-1.0C and WC-10SS-1.2C composites. 